\section{Differentiation between carbachol and eserine during deprivation-induced drinking in the rat*}

\author{
JOHN SPENCER and FRANK A. HOLLOWAY† \\ University of Oklahoma Health Sciences Center, Oklahoma City, Okla. 73190
}

Direct application of carbachol to various diencephalic or limbic regions of the rat brain enhanced water intake over saline baseline at $0-, 9-$, and $23-\mathrm{h}$ deprivation, while at $47 \mathrm{~h}$ no differences were seen. Application of eserine produced an increase in water intake at only $0-h$ deprivation, while norepinephrine had no effect at any level of deprivation. These results would suggest that endogenous cholinergic mechanisms may not mediate natural thirst in the rat.

It is a well-established finding that either carbachol or eserine produces an increase in water intake when administered to a variety of limbic or diencephalic sites in the rat brain (Fisher \& Coury, 1962, Grossman, 1962, Miller \& Chien, 1968).

These results have led to the hypothesis (see review by Levitt, 1971) that cholinergic mechanisms are the substrate for drinking behavior. One of the problems with this hypothesis is that it is not altogether clear that these same cholinergic mechanisms are operating in equal strength for naturally (deprivation) induced thirst. Kirkstone \& Levitt (1970) reported that centrally injected carbachol produced increases (relative to saline controls) in water intake of rats water-deprived for 9,15 , or $23 \mathrm{~h}$; however, centrally injected atropine (cholinergic blocking agent), while virtually abolishing. carbachol-elicited drinking, only partially depressed deprivation-induced thirst. These findings would seem to argue for the involvement of more than one mechanism during deprivation-induced drinking.

We suggest that natural thirst may not be specifically mediated by the release of endogenous acetylcholine (Ach). As a test for this suggestion, eserine or carbachol is injected within the same animal during various levels of water deprivation. Eserine (physostigmine sulfate) blocks the action of acetylcholinesterase, permitting an accumulation of any endogenous Ach and thus activating cholinergic receptors. If, however, endogenous $\mathrm{Ach}$ is not increased

* This research was supported by Grants 14702 and 13822 from the National Institute of Mental Health.

†ddress reprint requests to: John Spencer, Department of Psychiatry \& Behavioral Sciences, University of Oklahoma Health Sciences Center, 800 Y.E. 13. P.O. Box 26901. Oklahoma City. Okla. 73190 . (relative to $0 \mathrm{~h}$ deprivation) during various levels of deprivation-induced thirst, eserine would not potentiate water intake over various deprivation baseline control levels. In contrast, the application of carbachol during deprivation could act directly at the postsynaptic membrane to activate cholinergic receptors and induce additional drinking, independent of any fluctuation in the amount of endogenous Ach release. An attempt is also made in the present investigation to establish whether injections of norepinephrine interact with various levels of deprivation-induced thirst.

The Ss were 14 male albino rats of the Sprague-Dawley strain, 90-120 days old at the beginning of testing. Under sodium pentobarbital $(60 \mathrm{mg} / \mathrm{kg})$, double-wall cannulae (23 g, Plastic Products) were bilaterally implanted into the lateral hypothalamus $(\mathrm{N}=6)$, the preoptic area $(\mathrm{N}=6)$, or the lateral septal region $(\mathrm{N}=2)$. The DeGroot (1959) stereotaxic coordinate system was used.

The four drugs that were tested included isotonic saline, carbachol (carbamylcholine chloride, $22 \mathrm{x}$ $10^{-10} \mathrm{M}$ ), eserine (physostigmine sulfate, $\left.2.9 \times 10^{-8} \mathrm{M}\right)$, and norepinephrine (levaterenol bitartrate, $\left.647 \times 10^{-10} \mathrm{M}\right)$. The experimental drugs were dissolved in an isotonic saline solution. In each experimental session, 1 microliter was injected into each of the bilaterally implanted cannulae. The concentration of the drugs was based on preliminary work in our laboratory and on work by other investigators (Miller, Gottesman, \& Emery, 1964; Miller \& Chien, 1968), which showed that the above concentrations consistently elicited eating or drinking. In agreement with Miller et al (1964), we did note that carbachol-induced drinking was seen at concentrations as small as $2.5 \mathrm{x}$ $10^{-10} \mathrm{M}$. Concentrations greater than METHOD
$24 \times 10^{-10} \mathrm{M}$ did not consistently elicit drinking, but instead induced seizure activity.

All Ss were first tested at 0 -h water deprivation to establish that the sites were positive $(5 \mathrm{ml}$ of water consumed within $60 \mathrm{~min}$ following injection of carbachol or eserine and $2.5 \mathrm{~g}$ of food for the norepinephrine injection). Ss that met these criteria were used for the investigation.

The testing sequence was as follows: (1) Each $S$ received a 5-day baseline of saline injections; (2) on Day 6 , each $S$ received injections of either carbachol or eserine in a randomized order; (3) each $S$ received 3 additional days of saline baseline; and (4) on Day 10 , each $S$ was injected with norepinephrine. During the $1-h$ test session, only water was available. A 4-day rest period intervened before a new level of deprivation was examined.

The four water-deprivation conditions were $0,9,23$, and $47 \mathrm{~h}$. These conditions were randomized as to the order in which they were given. All Ss were tested in their home cages. Following the experiment, the Ss were sacrificed and histological verification was made of the cannula tracks.

\section{RESULTS}

The location of the cannulae for the lateral hypothalamic placements ranged from an AP of 4.2 to $6.0, \mathrm{RL}$ of 1.0 to 2.0 , and $\mathrm{V}$ of -2.0 to -3.5 ; for the preoptic area, the AP ranged from 7.4 to 8.0 , the $\mathrm{RL}$ from 1.5 to 3.0 , and $V$ from -1.5 to -2.5 ; and for the septal placements, the AP was from 7.0 to 8.0 , RL from 1.0 to 1.5 , and $\mathrm{V}$ from 1.0 to -2.5 .

A comparison was made between the three brain sites where the cannulae were implanted. Since none of these sites differed as to the effect of any of the drugs on water intake at any level of deprivation, all of the data was pooled for the analysis. A 4 by 4 repeated-measures factorial analysis of variance revealed a significant Drug by Deprivation Level interaction $(F=$ 3.29 , df $=9 / 117, p<.01)$. The main effects of drugs $(F=11.22$, df $=3 / 39$, $\mathrm{p}<.01)$ and of deprivation levels $(\mathrm{F}=$ 12.4 , df $=3 / 39, \mathrm{p}<.01$ ) were also significant. Referring to Fig. 1, with each increasing level of water deprivation, the mean baseline water intake was significantly greater than the immediately lower level. At $0-h$ deprivation, both carbachol and eserine produced a significant water intake over this saline baseline condition, while norepinephrine had no effect on water consumption, thus demonstrating the effectiveness of the cholinergic compounds in these sites. However, the amount of carbacholand eserine-induced drinking at $0-h$ deprivation did not differ significantly. 


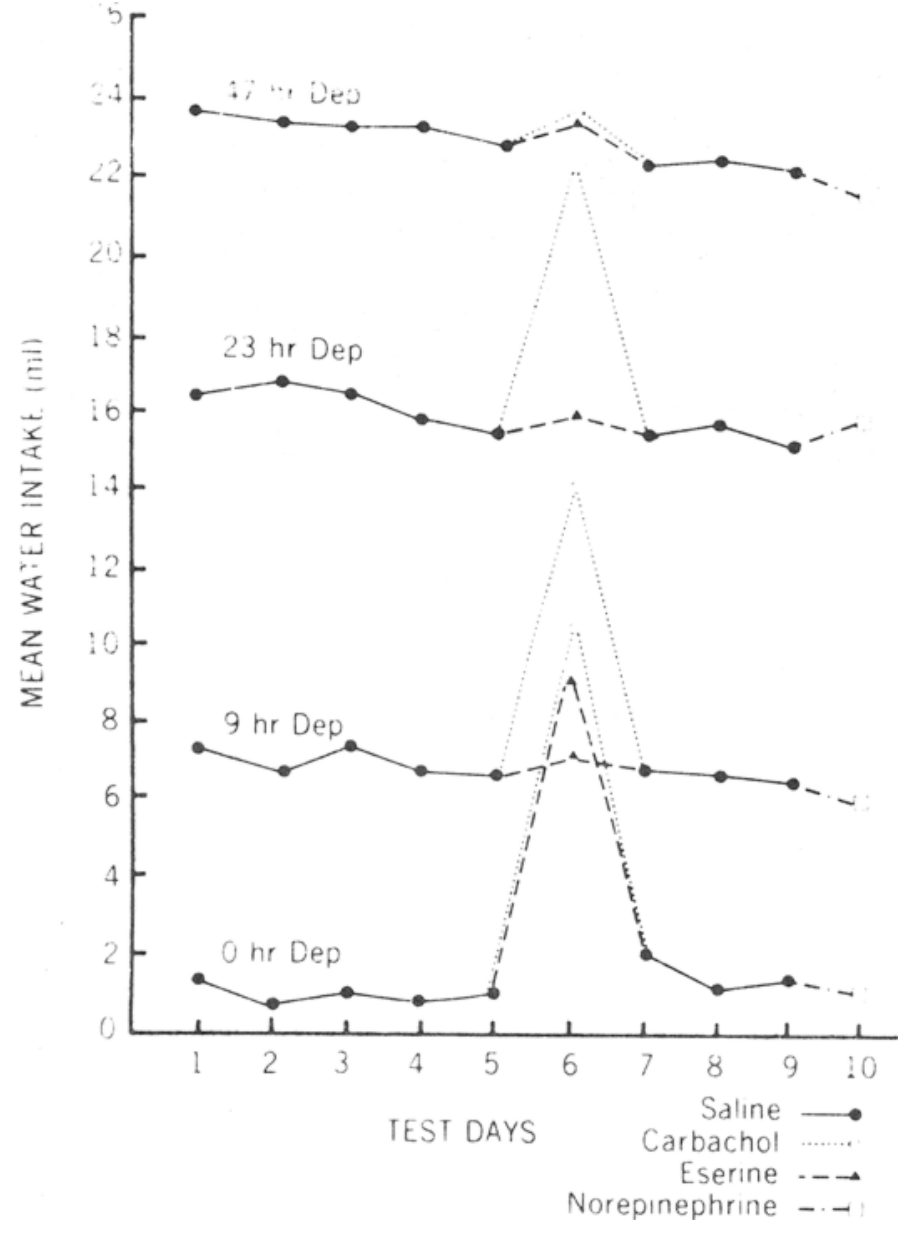

Fig. 1. Comparison of saline, carbachol $\left(22 \times 10^{-10} \mathrm{M}\right)$, eserine $\left(2.9 \times 10^{-8} \mathrm{M}\right)$, and norepinephrine $\left(647 \times 10^{-10} \mathrm{M}\right)$ during four different levels of water deprivation.

At 9- and 23-h deprivation, carbachol, but neither eserine nor norepinephrine, produced a significant intake, while at $47 \mathrm{~h}$ none of the drugs produced an increase in water intake when compared to the saline baselines. Between-group comparisons were made by the Scheffé test with p set at .01 .

\section{DISCUSSION}

The results of the present investigation are consistent with Levitt \& Baley's (1970) reported finding of diffuse limbic and diencephalic sites that are responsive to both carbacholand eserine-elicited drinking at 0 -h deprivation. The data from the present study also replicate Kirkstone \& Levitt's (1970) results, which show that an additive interaction exists at 9 and 23-h deprivation levels between carbachol and water deprivation. We found that neither eserine nor norepinephrine induced additional drinking when the Ss were water deprived.

The septal, preoptic, and lateral hypothalamic areas were examined in the present investigation because they are representative of sites producing carbachol- or eserine-elicited drinking. However, because of the diffuse nature of the "cholinergic drinking circuit," other areas may show different types of interactions between carbachol or eserine and water-deprivation level. While our findings cannot unequivocally posit that cholinergic receptors don't fire during water-deprivation conditions, endogenous cholinergic activity at the sites examined is not mediating additional water intake at 9,23 , or $47 \mathrm{~h}$ of deprivation. Miller \& Chien (1968) reported that at very low levels of deprivation $(5 \mathrm{~h})$, eserine-induced drinking was seen. It is unclear, though, whether or not the water-deprivation level they chose activated any "natural thirst system," since the difference in amount of water drunk during the 0 - and 5-h deprivation conditions for the saline injections was negligible.

If only cholinergic processes were mediating deprivation-induced thirst, the interaction between deprivation and cholinergic drug should be multiplicative. That is, increasing amounts of water deprivation should potentiate the absolute amount of cholinergic-induced drinking. The amount of drinking observed in this investigation increased by $9 \mathrm{ml}$ when carbachol was injected at $0 \mathrm{~h}$. At 9 . and 23-h deprivation, the amount of carbachol-induced drinking increased by only 7 and $6 \mathrm{ml}$, respectively, when compared to the saline condition. Thus, as in the Kirkstone \& Levitt study (1970), carbachol injections only induced a relatively fixed amount of water intake and did not interact multiplicatively with deprivation.

It is possible that noncholinergic activity increases with deprivation, thus partially mediating natural thirst and partially occluding or inhibiting activity in cholinergic neurons. A reduction in the amount of, or complete lack of, endogenous cholinergic activity during water deprivation would be consistent with the reported finding that eserine fails to induce additional drinking at 9,23 , or $47 \mathrm{~h}$ of deprivation. At the $47-\mathrm{h}$ deprivation level, even carbachol failed to induce additional water intake, perhaps by the complete occlusion or inhibition of cholinergic neurons produced by the high level of deprivation-induced activity in the "natural thirst system."

Additional evidence for a modulation of thirst by noncholinergic processes is provided by Blass \& Chapman (1971), who demonstrated that intracranial injections of atropine do not completely inhibit drinking induced by systemic injections of renin or by systemic cellular dehydration. Work by Giardina \& Fisher (1971) also indicates that atropine will not block drinking induced by angiotensin or isoproterenol (beta adrenergic agonist) injections. Levitt \& Buerger (1970) have demonstrated that combined injections of carbachol (intracranial) and $1.0 \mathrm{ml}$ of salt solution (subcutaneous) increased water intake over that to salt injection alone. Interestingly, injections of atropine reduced carbachol-induced drinking to a greater degree than it did to either deprivation- or salt-elicited drinking. These findings, in addition to those of the present study, imply that an exclusive relationship between cholinergic processes eliciting drinking and natural or artificially induced thirst has yet to be clearly established. The adrenergic compound norepinephrine (alpha receptor agonist) apparently does not interact with any "thirst system" at any level of deprivation, since this study failed to establish that this drug elicited 
drinking above saline baseline levels. Possible direct relationships between isoproterenol or angiotensin and naturally induced thirst remain to be investigated.

\section{REFERENCES}

BLASS. E. \& CHAPMAN. H. An evaluation of the contribution of cholinergic mechanisms to thirst. Physiology \& mechanisms to thirst.

DeGROOT, J. The rat hypothalamus in stereotaxic coordinates. Journal of Comparative Neurology. 1959, 113. 389-400.

FISHER, A. G, \& COERY, F.
Cholinergic tracing of a central neural circuit underlying the thirst drive. Science, 1962, 138,691-693.

GIARDINA. A., \& FiSHER. A. Effect of atropine on drinking induced by carbachol, angiotensin and isoproterenol. Physiology \& Behavior, 1971. 7,653-654 GROSSMAN, S. P. Direct adrenergic and cholinergic stimulation of hypothalamic mechanisms. American Journal of Physiology. 1962, 202,872-882

KIRKSTONE B \& LEVITT, R Interactions between water deprivation and chemical brain stimulation. Journal of Comparative \& Physiological Psychology, 1970,71, 334-340.

LEVITT, R. A. Cholinergic substrate for drinking in the rat. Psychological Reports. $1971,29,431-448$.
LEVITT, R. A., \& BALEY, R, P, Drinking elicited by injection of eserine or carbachol into the rat brain. Physiology \& Behavior, 1970, 5, 693-695.

LEVITT, R. A.. \& BUERGER. P. B. Interactions between cholinergic mechanisms and the salt arousal of drinking. Learning \& Motivation. 1970, 1 , 297-303.

MILLER, N., \& CHIEN CHUN-WUEI. Drinking elicited by injecting eserne into pre-optic area of the rat brain. Communications in Behavioral Biology. Part A. 1968, 1.61-63.

MILLER. N.. GOTTESMAN. K. \& EMERY, N. Dose response to carbachol and norepinephrine in rat hypothaiamus. American Journal of Physiology, 1964. 206. $1384-1388$ 